\title{
MAPPING EUROPE
}

\section{IMAGES OF EUROPE IN THE EUROVISION SONG CONTEST}

\author{
Mari Pajala \\ Media Studies \\ 20014 University of Turku \\ Finland \\ mari.pajala@utu.fi
}

\begin{abstract}
The Eurovision Song Contest (ESC) offers a unique viewpoint to the ways Europe has been imagined on television from the 1950s to the present. This paper looks at the use of a key visual symbol for Europe, the European map, to outline the history of the ESC's representation of Europe. Whilst the European map was rarely used during the first decades of the ESC, it became a central visual element of the show in the 1990s, a period of great political change in Europe. Since then, the ESC maps have pictured an ever widening image of Europe, gradually moving towards a dynamic, moving image of Europe and finally, dispensing with a coherent map of Europe altogether.
\end{abstract}

Keywords: Eurovision Song Contest, European Broadcasting Union, Europe, maps, television history

The Eurovision Song Contest (ESC) is a unique phenomenon in the history of European television. Set up by the European Broadcasting Union (EBU) in 1956, the contest has addressed a 'European' audience through great historical changes in Europe as well as in television culture. Broadcasters from seven Western European countries (Belgium, France, Italy, Luxemburg, The Netherlands, Switzerland, and West Germany) participated in the first ESC, held at a time when television was at an experimental stage in many European countries and live international television broadcasting was a novel possibility. The 2012 ESC took place in Azerbaijan, further east than ever before, at a time when the amount of available television programmes and viewing platforms has multiplied, but live television events seem to have maintained their special attraction.

Research on the ESC has developed in recent years, particularly around questions of representing nationality and negotiating European belonging in the contemporary, post-Cold War Europe. ${ }^{1}$ Whilst the ESC has been understood as a European event, the programme does not usually include a lot of explicit commentary on the concept of Europe. Apart from the customary opening greeting of 'Hello Europe', the most obvious recurring reference to Europe has been the use of the European map. Maps have been powerful symbols for Europe, outlining its changing boundaries, centres and peripheries. In this article I trace the historical development of ESC maps to chart how the programme has imaged Europe from the early years of television to the present. A historical perspective also helps to deepen the understanding of the contemporary ESC's relationship to Europe. ${ }^{2}$

${ }^{1}$ See for example Catherine Baker, 'Wild Dances and Dying Wolves: Simulation, Essentialization and National Identity at the Eurovision Song Contest,' Popular Communication, 6, 2008, 173-189; Miyase Christensen \& Christian Christensen, 'The After-Life of Eurovision 2003: Turkish and European Social Imaginaries and Ephemeral Communicative Space,' Popular Communication, 6, 2008, 155-172; Marijana Mitrović, ' "New Face of Serbia" at the Eurovision Song Contest: International Media Spectacle and National Identity,' European Review of History, 17, 2, 2010, 171-185; Paul Jordan, The Eurovision Song Contest: Nation Building and Nation Branding in Estonia and Ukraine, PhD thesis, Central and East European Studies, University of Glasgow, 2011.

${ }^{2}$ An earlier version of this paper was presented at the 'Eurovision and the New Europe' workshop (University of Warwick, June 2009) organized by Karen Fricker and Milija Gluhovic. 


\section{The ESC on Online Archives}

Over the decades the ESC and related national finals have accumulated a practically endless array of potential viewing material for scholars and enthusiasts. Online archives, particularly YouTube, have made the ESC's past available in unprecedented ways. Whereas old ESC broadcasts and national finals used to circulate internationally among fans and scholars as video or DVD recordings, it is now easy to find once rare clips on the Internet.

A programme like the ESC, produced in co-operation with the national host broadcaster and the EBU and consisting of a large number of individual music performances, poses challenges for online archiving due to copyright and compensation issues. Understandably then, institutionally curated online archives have relatively little material on the ESC and tend to concentrate on the media coverage of the contest rather than musical performances. EUscreen for

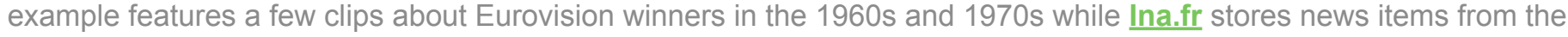
past decade and some clips from older Eurovision finals or related programmes. The Finnish YLE's online archive on the other hand features a large collection of songs from the Finnish Eurovision finals as well as clips from other programmes related to the ESC.

YouTube is by far the best resource for ESC related materials online thanks to its ability to disregard copyright concerns. Users can upload clips of television programmes on YouTube although they do not own rights to the programmes. This makes YouTube an unstable media archive, as the site may disable clips at copyright owners' request. ${ }^{3}$ As media scholar Alan McKee points out, YouTube is a particularly good resource for memorable 'moments of television' and clips that speak to the concerns of popular history. ${ }^{4}$ As a popular television event with a large international fan culture, the ESC is well represented on YouTube. Individual Eurovision entries have been perfect material for YouTube, which developed as a platform for short clips. Now that YouTube no longer limits the length of clips, even full length versions of the ESC have been uploaded on the site.

Most of ESC history is now available on YouTube, where nearly all contests up to 2003 (as well as some more recent editions) have recently been uploaded in full versions. Even the 1964 contest, the only one since 1957 not to survive as a television programme, is reconstructed on YouTube from the audio feed, photographs and the few short clips of the original television programme that exist.

Likewise, YouTube is a good source for performances from national Eurovision finals, especially from the newer editions but even from the first television decades if the programmes have been rerun as part of the recent 'memory boom'5 in television culture. For example the Portuquese Festival RTP da canção, an important television event particularly during the dictatorship era, is well represented on YouTube until the 1964 edition.

The EBU has recently started a project to restore and digitalise past ESC broadcasts in the run up to the $60^{\text {th }}$ ESC in 2015. The organisation has not announced yet whether the results will be made available to the public as well as to broadcasters. $^{6}$

\footnotetext{
${ }^{3}$ See Lucas Hilderbrand, 'YouTube: Where Cultural Memory and Copyright Converge,' Film Quarterly, 61, 1, 2007, 48-57.

${ }^{4}$ Alan McKee, 'YouTube versus the National Film and Sound Archive: Which Is the Most Useful Resource for Historians of Australian Television?' Television \& New Media, 12, 2, 2011, 154-173.

${ }^{5}$ Amy Holdsworth, '“Television Resurrections”: Television and Memory,' Cinema Journal, 47, 3, 2008, 139.

${ }^{6}$ Gordon Roxburgh, 'Dates Announced for 2013 Contest,' Eurovision Song Contest, 23 May 2012, http://www.eurovision.tv/page/ news? id=dates announced for 2013 contest; Jarmo Siim, 'EBU Starts Eurovision Archive Project,' Eurovision Song Contest, 8 October 2011, http://www.eurovision.tv/page/news? id=38943\& $\mathrm{t}=\mathrm{ebu}$ starts eurovision archive project.
} 


\section{A Western European Affair}

From the 1950s to the late 1980s the ESC represented the Cold War division of Europe without much explicit focus on the concept of Europe. Whilst the contest was conceptualised as a 'European' event, in practice this meant West European as participation was restricted to EBU members who mostly came from Western Europe. Eastern European broadcasters co-operated in an organisation of their own, Organisation Internationale de Radiodiffusion et de Télévision (OIRT). ${ }^{7}$ However, a clear East/West divide was complicated by Yugoslav television, which was an EBU member and participated in the ESC since 1961, and Finnish television, which was a member of both the EBU and OIRT.

During this period the European map was rarely used as a visual element in the ESC. When it was, the maps ignored the Cold War division in Europe that otherwise structured the contest. The 1963 ESC introduced the entries with a map of Europe.

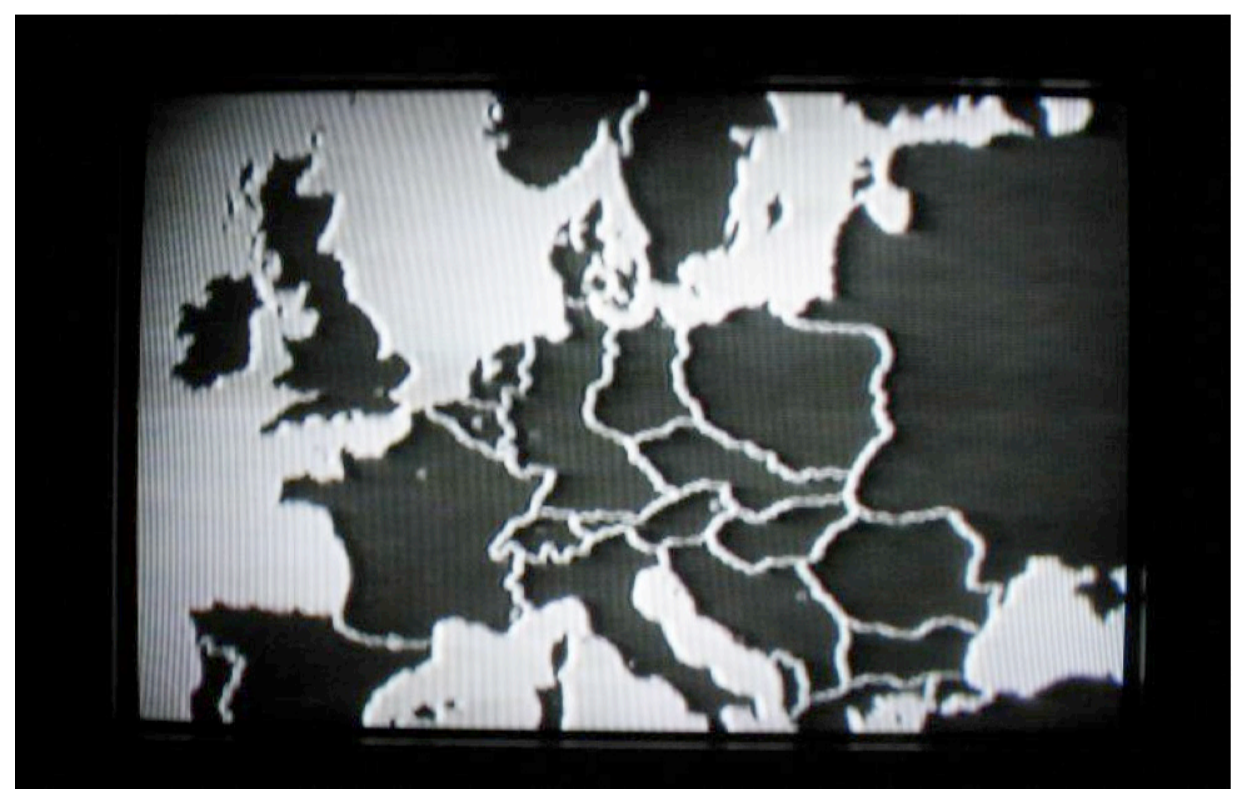

Fig. 1. ESC 1963, BBC 23 March 1963

The participating countries hardly fit the screen, with the northernmost parts of the Nordic countries and the southernmost parts of the Mediterranean countries cut off the map. However, the map makes no distinction between participating countries and the socialist countries whose broadcasters were not EBU members. The situation is similar in the map used in the 1984 contest, with the exception that the framing shifts according to the country being introduced, so that different parts of Europe fall off the map.

Whilst the organisation of the ESC embodied the geopolitical divisions in Europe after the Second World War, the maps picture a unified Europe, with no visible East/West boundary. This was in line with the more general concerns of the EBU, which developed co-operation with OIRT from the late 1950s. The ESC was offered through OIRT's Intervision network from 1965 onwards, and for a while in the late 1960s, the contest acknowledged the Intervision audience. For example the 1970 contest opening credits features the text "The Netherlands welcome you at the Eurovision Song Contest 70 in Amsterdam" with a list of countries including Czechoslovakia, Bulgaria, Hungary, Soviet Union, Romania, Poland, as well as Tunisia and Brazil. Thus, whilst the ESC concentrated on creating a Western European community of competitors, juries and viewers, it also made some attempts to image a Europe without 
Cold War geopolitical divisions, or perhaps encouraged viewers to "look away from the division"8 that structured international relations even in television broadcasting.

\section{Promoting Western European Integration}

For a short period from the late 1980s to the early 1990s, the ESC actively promoted Western European integration. In the late 1980s, the European Communities (EC) developed more intensive political co-operation in preparation for the establishment of the single market (planned for 1992) and the Maastricht Treaty (1992), which formed the European Union and laid the basis for a common European currency. At the same time, the ESC began discussing Europe more explicitly than before, using symbols of the EC rather than the European map.

The 1987 ESC was held in Brussels on Europe day, which the host of the show introduced as the birthday of both the EC and Europe, equating Europe with the EC. The interval act featured a flautist playing Beethoven's 'Ode to Joy' the EC's designated anthem of Europe - over a montage sequence of varying landscapes, culminating with a view of the EC flag on a mountaintop.

Likewise, the interval act of the following year's contest, a music video for a song by the Irish band Hothouse Flowers, follows the group in the twelve EC member countries, with the EC flag superimposed over the face of the singer at a key point of the song.

The culmination of the ESC's Western European 'pro-integration' period was the 1990 contest, where the recent events in Eastern Europe had inspired entries such as 'Brandenburger Tor' and 'Keine Mauer mehr'. The Italian winning song, 'Insieme: 1992' is a hymn to European integration, with lyrics reflecting on freedom and shared values and a refrain of 'Insieme (together), unite unite Europe'. The visual backdrop of yellow stars on blue once again brings to mind the EC flag.

These programmes equate Europe with the EC, a narrow definition even by Western European standards - at the time a little more than a half of the participating countries of the ESC were EC members. However, the ESC's image of Europe was about to change, as members of the OIRT joined the EBU in 1993 and gradually entered the ESC. The Swedish host of the 1992 ESC described the situation poignantly: "The map of Europe is rapidly changing. Old countries disappear and new countries are being born. And when east is no longer east and west is no longer west, Europe has become greater." Since then, the ESC has indeed concentrated on expanding Europe.

\section{Expanding Europe}

The European map became a central visual element of the ESC in the late 1990s, beginning in 1996 when maps were featured in the 'postcard films' that introduce the entries. Different versions of the European map were then used to visualise the voting from 1998 to 2008. It is hardly a coincidence that the European map gained prominence in the ESC at a time when Europe was undergoing great changes with the establishment of new countries and the expansion of the European Union. In the ESC, the arrival of new participating countries began a period of extending Europe eastwards. The number of participants has grown from 23 in 1992 to 43 in 2011, enabled by the addition of two semi-finals. 
The European maps of the ESC create an ever-widening image of Europe. The framing in the 1996 map is already wider than in the 1963 ESC, showing all the Nordic countries as well as some of Northern Russia, North Africa and the Middle East.

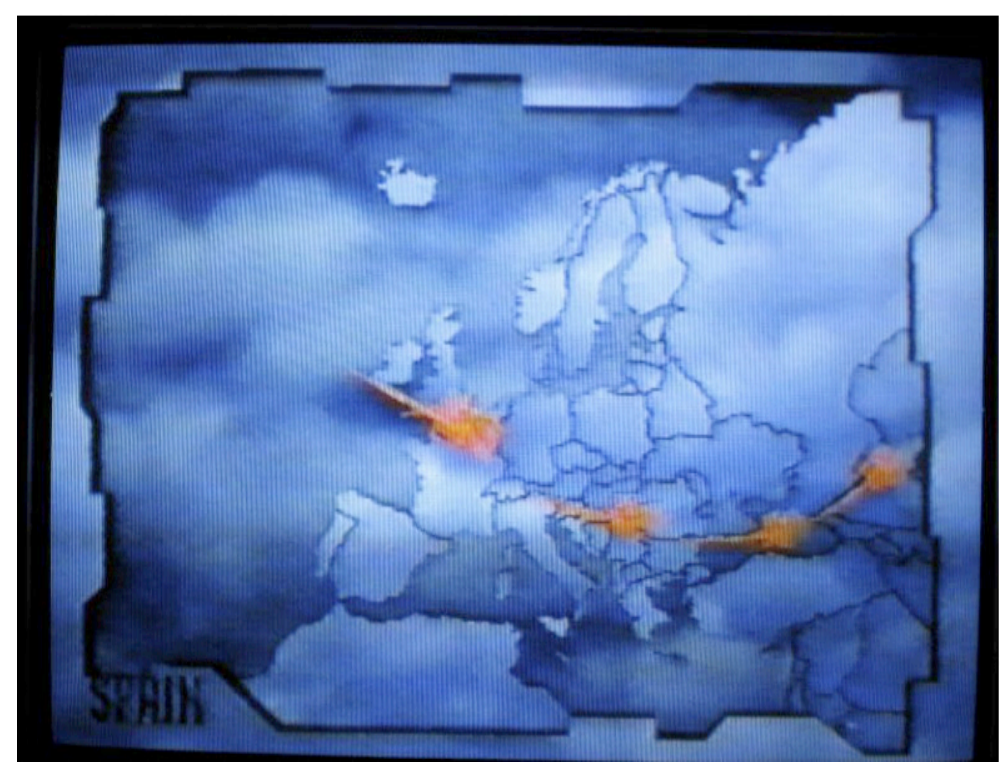

Fig. 2. ESC 1996, NRK 18 May 1996

At the beginning of the 2000s the boundaries of the maps moved further south and east and by 2007 the map extended even further to accommodate new participants Armenia and Georgia. Thus the ESC's image of Europe became more inclusive: Western Europe lost its central position and participating countries were not left in the margins visually. The maps also give increasing room to North Africa and the Middle East, highlighting the fact that Europe has no clear boundaries.

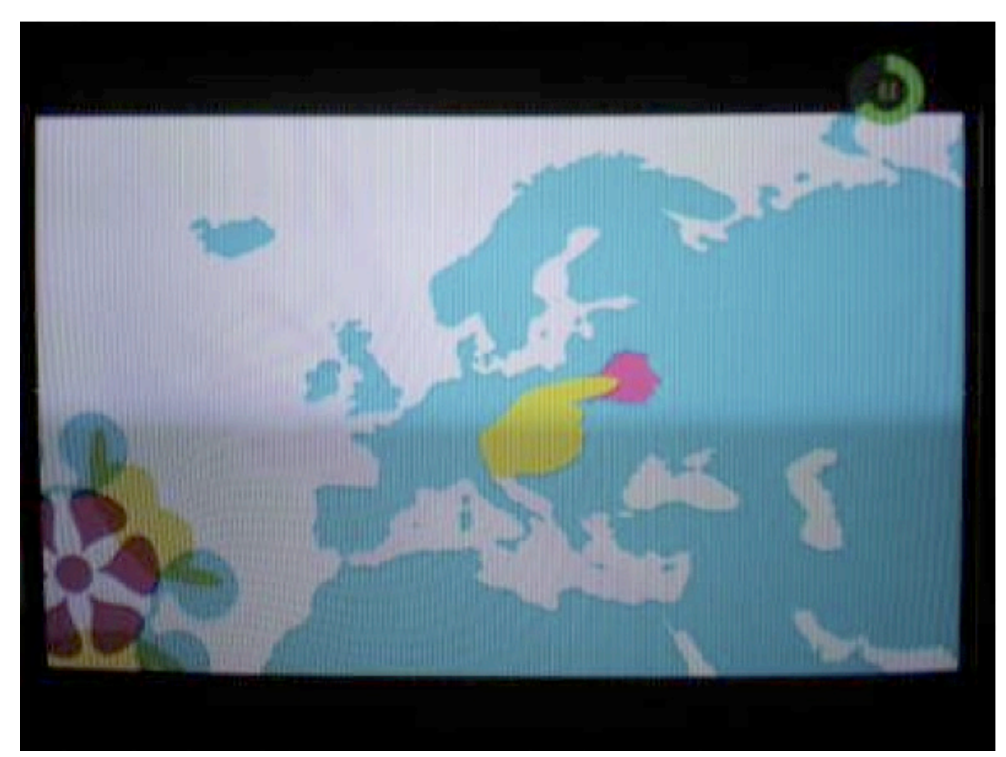

Fig. 3. ESC 2007, YLE 12 May 2007

The ESC maps are generally very bare, showing the outlines of earth and sea and excluding natural features and towns. Moreover, they have developed towards ever greater abstraction over the years. While the earlier maps 
featured national borders, since 2001 these have been left out (apart from a customary zoom-in to the country whose votes will be shown next). The 1998, 1999 and 2001 maps differentiated the participating countries from nonparticipants with different colours, producing very patchy images of Europe. Since 2001, when the ESC was held in the former Intervision territory for the first time, the maps have not singled out participating countries. Thus, the ESC maps produce a stylized image of Europe with no clear boundaries, emphasizing unity over national borders.

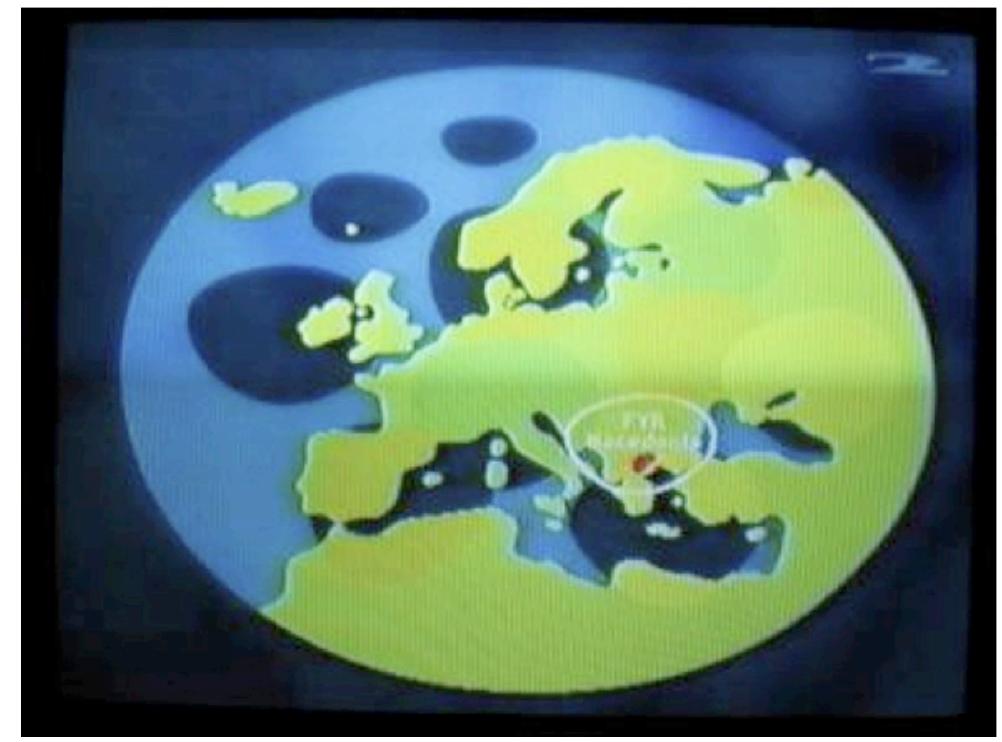

Fig. 4. ESC 2002, ETV 25 May 2002

The ESC's image of Europe is much wider than that of the European Union for example. Consequently, for a period in the early 2000s, new winners such as Estonia and Ukraine could use the ESC as a vehicle to proclaim their 'return to Europe'. ${ }^{9}$ Winning and staging the ESC has had great symbolic importance for new participating countries. ${ }^{10}$

\section{Europe in Motion}

With the development of digital imaging technology, ESC maps have acquired movement, picturing Europe in less stable ways than before. The 2006 map blurs the boundaries of Europe. Instead of the customary outline of Europe, we see carefully drawn countries emerge from a shapeless background. This moving map could be read as an illustration of the difficulties of representing Eurovision's ever-widening Europe.

\footnotetext{
${ }^{9}$ Paul Jordan, The Eurovision Song Contest: Nation Building and Nation Branding in Estonia and Ukraine, PhD thesis, Central and East European Studies, University of Glasgow, 2011.

${ }^{10}$ Göran Bolin, 'Visions of Europe: Cultural Technologies of Nation States,' International Journal of Cultural Studies, 9, 2, $2006,189-206$.
} 

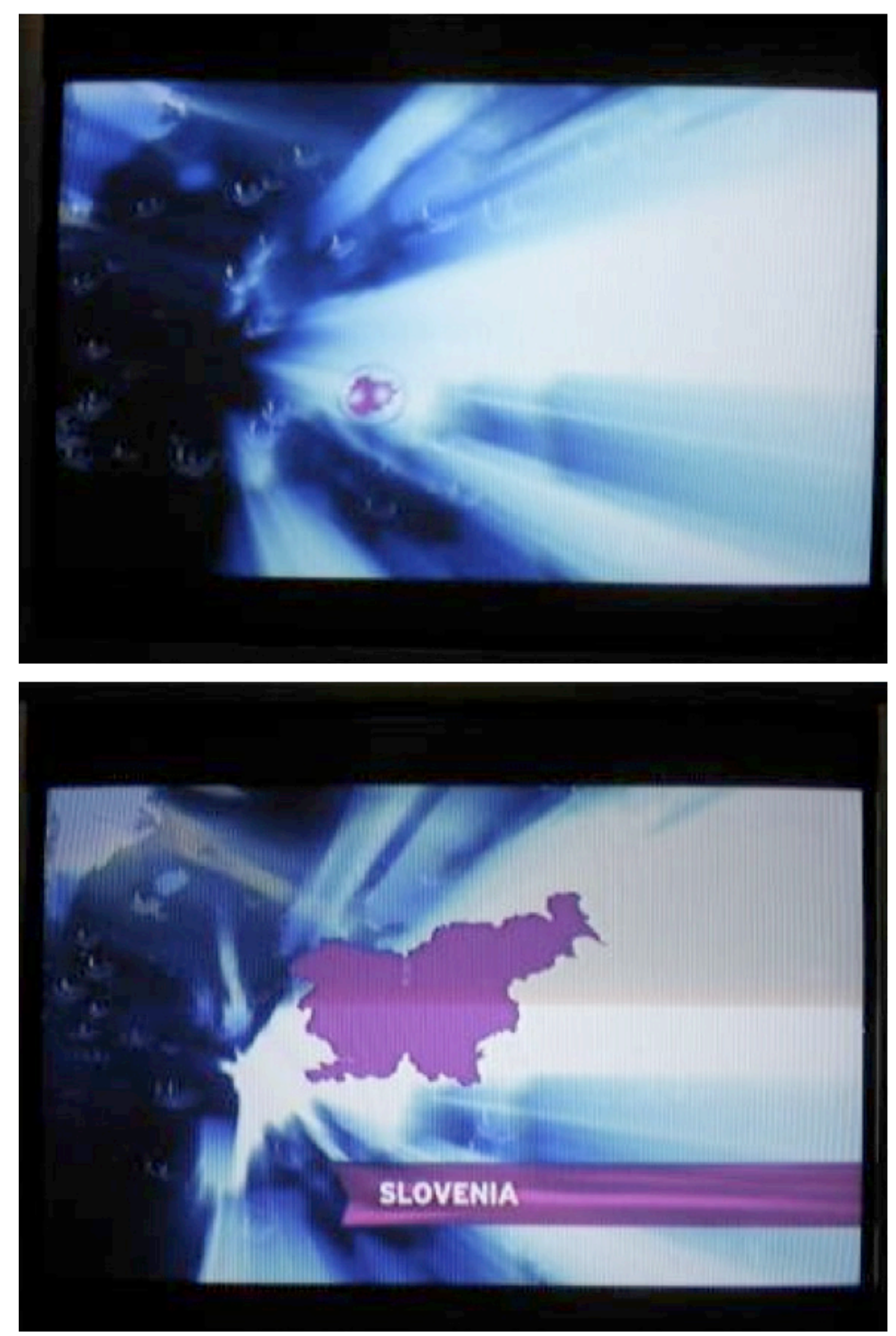

Fig. 5-6. ESC 2006, ERT 20 May 2006

In the 2007 contest on the other hand we first see a simple map of Europe with no national boundaries. A yellow finger appears, points at a country whose contours become briefly visible on the map, and as we cut to a close up of the country, it quickly dissolves into a colourful kaleidoscopic image.

These moving maps are illustrative of an era when the ESC takes part in renegotiating the cultural meanings of Europe. At the beginning of the 2000s the ESC was a cultural arena where countries in the former Eastern Europe could assert their Europeanness on terms defined by Western Europe. The Estonian and Latvian winning songs in 2001 and 2002 were pronouncedly 'Western' in style. However, the Turkish victory in 2003 opened a period during which South-East European music traditions were particularly successful in the ESC. As new (Ukraine, Serbia) or previously marginal Eurovision countries (Turkey and Greece) became highly successful participants in the ESC, the old Western Europe lost its once hegemonic position in the contest. As a consequence, it seems that European enlargement in the ESC stopped being 'just about getting bigger' and became 'a matter of cultural transformation'. ${ }^{11}$ 
This cultural transformation involves struggle. Accordingly, the ESC has been an arena for debate concerning power relations in Europe in recent years, with recurring complaints in old participating countries about the increasing prominence of so-called Eastern European countries.

\section{A Post-European Period?}

The European map has disappeared from the ESC since the 2009 contest held in Moscow. As the number of participants has grown, there has been a need to streamline the voting process, which probably explains why the graphics have been simplified and the map no longer used. However, it seems significant that the European map was left out just when the ESC was held in Russia for the first time. Fitting all of Russia on the same map with Western Europe would have produced a very different map from the one Eurovision viewers are used to. Subsequent contests in Norway and Germany have done without the European map as well. With the 2012 contest held in Azerbaijan, where conventional geographical definitions place the border between Europe and Asia, the programme's relationship to the concept of Europe may be undergoing a change. In Azerbaijan, staging the ESC was treated as a valuable chance to represent the country for an international audience, but it is debatable whether the ESC still has symbolic power as a marker of European belonging. On the other hand, it may be that the absence of symbols of Europe is temporary and the ESC will continue to play a role in imaging Europe.

\section{B i o graphy}

Mari Pajala is a research fellow at the Department of Media Studies, University of Turku working on an Academy of Finland funded project on television as a technology of memory. Her publications include Ranking Differences: The Eurovision Song Contest, Nationality and Television History (in Finnish) and articles on television history, contemporary television culture and feminist media studies.. 